\title{
Variant Allele Frequency
}

National Cancer Institute

\section{Source}

National Cancer Institute. Variant Allele Frequency. NCI Thesaurus. Code C154665.

The relative rate of occurrence of a specific variant allele within a population. 